\title{
Efeito da Casearia sylvestris no reparo ósseo com matriz óssea bovina desvitalizada em ratos ${ }^{1}$
}

\author{
Effect of Casearia sylvestris on bone repair with devitalized bovine bone matrix in rats
}

\author{
Maria Cristina Pita Sassioto ${ }^{2}$, Normandis Cardoso Filho ${ }^{3}$, Gilberto Gonçalves Facco ${ }^{4}$, Suelen Trentin Sodré , Noelton \\ Neves $^{5}$, Sônia Ueda Purisco ${ }^{5}$, Adriana Gomes de Farias ${ }^{5}$
}

1. Trabalho realizado na Disciplina de Fisiologia, Curso de Farmácia e Bioquímica da Universidade para o Desenvolvimento do Estado e da Região do Pantanal (UNIDERP), Campo Grande-MS.

2. Mestre em Ciências da Saúde, Professor do curso de Farmácia e Bioquímica da UNIDERP.

3. Mestre em Farmácia, Coordenador do curso de Farmácia e Bioquímica da UNIDERP.

4. Mestre em Patologia, Professor do curso de Farmácia e Bioquímica da UNIDERP.

5. Acadêmico do $7^{\circ}$ semestre do curso de Farmácia e Bioquímica da UNIDERP

\section{RESUMO}

Objetivo: Estudar o efeito do decocto 5\% de Casearia sylvestris no reparo de defeito femoral preenchido com matriz óssea bovina desvitalizada. Métodos: Vinte e quatro ratos Wistar, machos e adultos foram distribuídos aleatoriamente em dois grupos com 12 animais. Defeitos femorais bilaterais, com $2 \mathrm{~mm}$ de diâmetro, foram produzidos na diáfise femoral e preenchidos com matriz óssea bovina desvitalizada. O grupo experimento recebeu $1 \mathrm{~mL}$ de decocto $5 \%$ de Casearia sylvestris, por gavagem, durante o período de seguimento; o grupo controle recebeu $1 \mathrm{~mL}$ de água destilada. Os animais foram sacrificados com 10,20 ou 30 dias e o tecido ósseo presente na área operatória quantificado. Aplicou-se o teste " $t$ " de Student para comparação das médias de formação óssea obtidas em cada período estudado (10, 20 e 30 dias), em nível de significância de 5\% (p $\leq 0,05)$. Resultados: A neoformação óssea foi menor nos animais do grupo experimento nos seguimentos de $10(p=0,0000), 20(p=0,0049)$ e 30 dias $(\mathrm{p}=0,0003)$. Conclusão: O decocto $5 \%$ de Casearia silvestris promove atraso na cronologia do processo de reparação óssea em defeitos ósseos preenchidos com matriz óssea bovina desvitalizada, em ratos, na dose e período estudados.

Descritores: Osso e Ossos. Ratos.

\begin{abstract}
Purpose: To evaluate the use of devitalized bovine bone matrix with Casearia sylvestris decoct treatment to regenerate femoral defect in rats. Methods: Twenty-four adult male Wistar rats were used in this study. Bilateral femoral defects with $2 \mathrm{~mm}$ diameter were surgically produced and fulfilled with particulate inorganic bovine bone. Casearia sylvestris decoct treatment was realized in the preoperative period. The animals were sacrificed 10, 20 and 30 postoperative days and specimens were submitted to histomorphometric evaluation. The data was submitted a statistical evaluation with Student t-test. Results: The bone formation was reduced in the experimental animals at $10(p=0,0000), 20(p=0,0049)$ and $30(p=0,0003)$ postoperative days. Conclusion: The association of Casearia sylvestris decoct treatment and the fulfillment of defect with particulate inorganic bovine bone seemed to decrease bone formation.
\end{abstract}

Key words: Bone and Bones. Rats.

\section{Introdução}

A osteogênese necessária ao reparo de defeitos ósseos pode ser influenciada por vários fatores, como as matrizes ósseas utilizadas como material de implante e os fármacos com ação direta ou indireta no metabolismo ósseo $0^{1,2,3,4}$. 
Vários tipos de biomateriais e suas associações experimentais com diversas substâncias vêm sendo estudados no processo de reparação óssea, considerando que o tecido ósseo é um dos poucos tecidos de mamíferos capaz de reconstituir a estrutura lesada em sua forma original com restauração da estrutura histológica e propriedades mecânicas ${ }^{4,5,6}$.

Contudo, a reconstrução tecidual de lesões ósseas causadas por traumas, processos infecciosos, neoplasias ou anomalias do desenvolvimento, ainda representa um desafio em procedimentos ortopédicos e odontológicos, direcionando os estudos à investigação de substitutos do osso autógeno e de agentes farmacológicos que facilitem sua integração ${ }^{2,4 .}$.

A matriz bovina desvitalizada é uma hidroxiapatita natural de composição química e porosidade semelhantes à humana, que quando utilizada de forma isolada ou em associação com fármacos para preencher defeitos ósseos, comporta-se como arcabouço para as células mesenquimais do osso hospedeiro invadirem e se diferenciarem em tecido ósseo ${ }^{1,2,4,7,8}$.

A Casearia sylvestris, também conhecida como guaçatonga, café bravo ou erva de bugre, tem uma longa história na medicina folclórica brasileira. ${ }^{9} 10$ A decocção da folha é preparada tanto para aplicação tópica como para ser tomada como antiinflamatório, antiviral, antiulceroso e como anestésico e hemostático para lesões de mucosas e pele $\mathrm{e}^{11,12}$.

A estrutura química da Casearia sylvestris é bastante complexa; suas folhas contêm fitoquímicos (diterpenos) com ação antitumoral, antifúngica, antibiótica e inibidora da replicação do vírus HIV e sua ação antiinflamatória foi considerada similar à do piroxicam e meloxicam, em $\operatorname{ratos}^{13,14,15}$.

Considerando os aspectos acima, julgou-se pertinente o estudo experimental do reparo de defeitos ósseos preenchidos com matriz óssea bovina desvitalizada, em ratos tratados com decocto $5 \%$ de Casearia sylvestris.

\section{Métodos}

Os procedimentos foram realizados de acordo com o Animal Experimentation Ethics Committee. Foram utilizados 24 ratos Wistar ( $\mathrm{N}=48$ fêmures), machos, adultos, com peso médio de 275 gramas, procedentes do Biotério Central da UNIDERP, mantidos em gaiolas comunitárias com ração e água ad libitum e distribuídos aleatoriamente em dois grupos com 12 animais cada: grupo I (experimento) e grupo II (controle). Cada grupo foi subdividido em três subgrupos com quatro animais cada $(\mathrm{n}=8)$ : subgrupo A (10 dias), subgrupo B (20 dias) e subgrupo C (30 dias).

Procedimentos anestésicos: os animais foram pesados em balança de precisão e anestesiados por solução 1:1 de xilazina $\left(20 \mathrm{mg} \cdot \mathrm{mL}^{-1}\right)$ e quetamina $\left(50 \mathrm{mg} \cdot \mathrm{mL}^{-1}\right)$, na dosagem de $0,1 \mathrm{~mL} \cdot 100 \mathrm{~g}^{-1}$ de peso, por via intramuscular.

Procedimentos operatórios: realizada a tricotomia, fezse incisão longitudinal de $20 \mathrm{~mm}$ em face lateral de coxa, divulsão romba da musculatura com exposição da diáfise femoral, incisão e elevação periostal, confecção de defeito ósseo com broca metálica de $2 \mathrm{~mm}$ de diâmetro acoplada em perfurador elétrico de baixa rotação, interessando córtex lateral e medular óssea, mantendo-se íntegra a cortical medial, em ambos fêmures. Os defeitos produzidos foram preenchidos com matriz óssea bovina desvitalizada e a incisão fechada com sutura contínua com fio monofilamentado de poliamida 4-0.

Procedimentos pós-operatórios: após recuperação anestésica foi permitido aos animais apoio imediato dos membros operados sem nenhum tipo de imobilização externa, sendo mantidos nas gaiolas, com água e ração ad libitum. Fezse a decocção de $1 \mathrm{~g}$ de folhas pulverizadas de Casearia sylvestris em $20 \mathrm{~mL}$ de água destilada, submetendo o decocto a análise qualitativa por cromatografia em camada delgada para confirmação da presença de flavonóides, saponinas e taninos; doseamento dos flavonóides rutina e quercetina por cromatografia líquida de alta eficiência e doseamento dos polifenóis totais. $\mathrm{O}$ decocto foi armazenado em frasco âmbar com tampa rosqueada, sob refrigeração $\left(10-14^{\circ} \mathrm{C}\right)$, com renovação de $50 \mathrm{~mL}$ a cada três dias. Os animais do grupo experimento foram tratados diariamente, por gavagem, com $1 \mathrm{~mL}$ de decocto 5\% de Casearia sylvestris e os animais do grupo controle com a mesma quantidade de água destilada até o cumprimento dos seguimentos de 10,20 e 30 dias, quando quatro animais de cada grupo foram pesados e sacrificados por inalação contínua de éter etílico.

Procedimentos histológicos: os fêmures foram dissecados e fixados em formol tamponado $10 \%$, descalcificados e submetidos a processamento histológico de rotina no Laboratório de Histopatologia da UNIDERP. Cortes histológicos de quatro micra foram corados com hematoxilina-eosina e submetidos a avaliação histológica com utilização de microscópio óptico acoplado a conjunto para fotomicrogafia, ambos adaptados a microcomputador com softwares WinTV e ImageLab 2-3, com finalidade de quantificar o tecido ósseo na área do defeito produzido operatoriamente.

Procedimentos estatísticos: aplicou-se o teste " $t$ " de Student para comparação das médias de formação óssea, do grupo controle e experimental, obtidas em cada período estudado (10, 20 e 30 dias), em nível de significância de 5\% (p $\leq 0,05)$.

\section{Resultados}

No decorrer do experimento todos os animais ganharam peso e não houve nenhuma morte.

A análise histológica por microscopia óptica mostrou progressiva neoformação óssea adjacente às margens do defeito operatório e aos fragmentos de matriz óssea bovina desvitalizada (Figura 1). A análise quantitativa do tecido ósseo presente na área do defeito operatório está exposta na Tabela 1. 

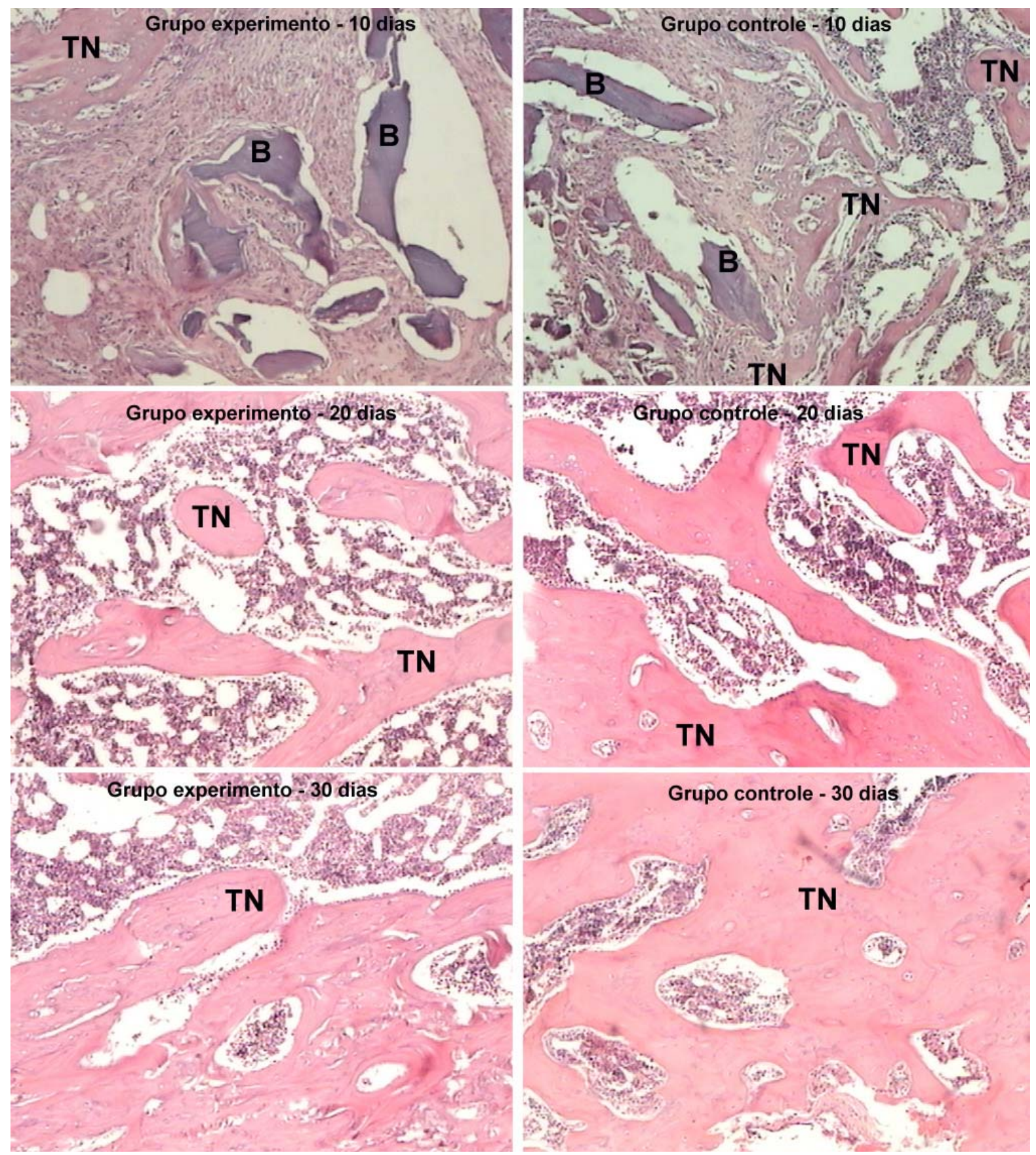

FIGURA 1 - Fotomicrografias mostrando o aspecto histológico do defeito ósseo nos grupos experimento e controle (HE - 40x). Observa-se menor neoformação óssea nos animais do grupo experimento em todos os períodos de seguimento. TN: osso neoformado; B: fragmentos de matriz óssea bovina desvitalizada 
TABELA 1 - Análise quantitativa da formação óssea nos grupos experimento e controle com respectivos subgrupos. Valores em porcentagem

\section{GRUPO I - EXPERIMENTO}

\begin{tabular}{ccc}
\hline $\begin{array}{c}\text { Subgrupo IA } \\
\text { (10 dias) }\end{array}$ & $\begin{array}{c}\text { Subgrupo IB } \\
\text { (20 dias) }\end{array}$ & $\begin{array}{c}\text { Subgrupo IC } \\
\text { (30 dias) }\end{array}$ \\
\hline 16,32 & 36,58 & 52,22 \\
\hline 16,27 & 39,54 & 57,64 \\
\hline 15,34 & 35,56 & 58,70 \\
\hline 14,96 & 33,97 & 52,23 \\
\hline 15,69 & 38,25 & 58,25 \\
\hline 15,65 & 38,64 & 56,80 \\
\hline 16,03 & 36,84 & 59,64 \\
\hline 14,97 & 37,26 & 58,25 \\
\hline $\mathbf{1 5 , 6 5} \pm \mathbf{0 , 5 3 6}$ & $\mathbf{3 7 , 0 8} \pm \mathbf{1 , 7 8 0}$ & $\mathbf{5 6 , 7 2} \pm \mathbf{2 , 8 8 8}$
\end{tabular}

\section{GRUPO II - CONTROLE}

\begin{tabular}{ccc}
\hline $\begin{array}{c}\text { Subgrupo IIA } \\
\text { (10 dias) }\end{array}$ & $\begin{array}{c}\text { Subgrupo IIB } \\
\text { (20 dias) }\end{array}$ & $\begin{array}{c}\text { Subgrupo IIC } \\
\text { (30 dias) }\end{array}$ \\
\hline 16,95 & 38,65 & 64,20 \\
\hline 17,23 & 38,79 & 62,38 \\
\hline 18,05 & 39,45 & 61,56 \\
\hline 17,89 & 40,23 & 62,55 \\
\hline 18,12 & 37,89 & 64,78 \\
\hline 17,69 & 40,56 & 63,56 \\
\hline 19,20 & 41,25 & 64,12 \\
\hline 18,22 & 39,55 & 63,89 \\
\hline $\mathbf{1 7 , 9 2} \pm \mathbf{0 , 6 8 2}$ & $\mathbf{3 9 , 5 5} \pm \mathbf{1 , 1 0 4}$ & $\mathbf{6 3 , 3 8} \pm \mathbf{1 , 1 0 0}$ \\
\hline
\end{tabular}
IA x IIA: Teste t com variâncias iguais - $\quad F(7,7)=0,6185 \quad \mathrm{p}=1,0000$ $\mathrm{t}=-7,3835 \quad \mathrm{p}=0,0000$
IB x IIB: Teste t com variâncias iguais - $\quad F(7,7)=2,6012 \quad \mathrm{p}=0,2308$ $\mathrm{t}=-3,3308 \quad \mathrm{p}=0,0049$
IC x IIC: Teste t com variâncias desiguais - $F(7,7)=6,8908 \quad \mathrm{p}=0,0224$ $t=-6,0984 \quad p=0,0003$

\section{Discussão}

Os biomateriais vêm tendo um uso crescente na ortopedia e odontologia, com a finalidade de preenchimento de cavidades ósseas e facilitação da formação óssea por proteção contra a invasão de tecidos não-osteogênicos competidores ${ }^{2,4}$.

A matriz óssea bovina desvitalizada foi selecionada para preenchimento das cavidades ósseas, neste trabalho experimental, por ser biocompatível, ter reserva de matéria prima suficiente, ser de baixo custo e fácil manuseio, podendo ser estocada em temperatura ambiente e não exigindo instrumental cirúrgico especial para sua aplicação ${ }^{2,4,6,7,8}$.

Como a osteogênese reparadora de defeitos ósseos, com ou sem uso de enxertia óssea, pode ser influenciada por fatores biológicos e físicos, promovendo aceleração ou retardando a reparação óssea ${ }^{4,8}$, decidiu-se estudar o efeito do decocto $5 \%$ de folhas de Casearia sylvestris na integração da matriz óssea bovina desvitalizada em defeitos ósseos femorais provocados operatoriamente, em ratos.

No decorrer do experimento não houve morte de nenhum animal e o ganho de peso apresentado por todos os animais da amostra demonstra que os procedimentos operatórios realizados, o biomaterial e o fitoterápico utilizados não interferem com o desenvolvimento normal do animal, no período estudado.
No estudo histológico observou-se neoformação de tecido ósseo justaposta às paredes do defeito e à superfície da matriz óssea bovina desvitalizada, com aspecto basófilo e sinais de reabsorção, demonstrando um arcabouço biológico adequado para a neovascularização e deposição óssea em todos os períodos de seguimento (Figura 1).

Nos animais tratados com decocto $5 \%$ de Casearia sylvestris, a formação óssea ocorreu em menor quantidade que nos animais do grupo controle (Tabela 1). Relacionamos o efeito inibidor da formação óssea demonstrado pelo decocto $5 \%$ de Casearia sylvestris à presença dos fitoquímicos com ação antiinflamatória, de forma semelhante ao efeito dos fármacos alopáticos antiinflamatórios não hormonais, que promovendo inibição da síntese de prostaglandinas na produção de efeito analgésico e antiinflamatório, causam diminuição do número de macrófagos, fibroblastos e fibras colágenas ${ }^{9,16}$, com efeito inibitório sobre a osteogênese.

\section{Conclusão}

A utilização de decocto $5 \%$ de Casearia silvestris promove atraso na cronologia do processo de reparação óssea e menor osteogênese em defeitos ósseos preenchidos com matriz 
óssea bovina desvitalizada, em ratos, na dose e período estudados.

\section{Referências}

1. Oliveira MG, Britto JHM, da Fonseca LAM. Avaliação microscópica do processo de reparo ósseo em tíbias de ratas, usando implantes de osso liofilizado bovino. Rev Odonto Cienc. 2001;16(34):242-50.

2. Sassioto MCP, Massaschi CM, Aydos RD, Silva AR, Takita LC, Figueiredo MJPSS, Bueno TAAO. Estudo morfológico do reparo de defeito ósseo preenchido com enxerto ósseo autógeno ou matriz óssea bovina, em ratos. Ensaios Ci. 2003; 7:543-50.

3. Sculean A, Berakdar M, Chiantella GC, Donos N, Arweiler NB, Brecx M. Healing of intrabony defects following treatment with a bovine-derived xenograft and collagen membrane. A controlled clinical study. J Clin Periodontol. 2003;30(1):73-80.

4. Sassioto MCP. Estudo morfológico do reparo de defeito ósseo com matriz óssea bovina desvitalizada e calcitonina, em ratos [Dissertação - Mestrado]. Programa Multiinstitucional de Pós-Graduação em Ciências da Saúde - Convênio Rede Centro-Oeste UnB-UFG-UFMS; 2004.

5. Braga FJC, Silva GM, König Jr B. Obtenção de Matriz mineral de osso bovino e a comprovação de sua biocompatibilidade. Rev Bras Cir Protese Implant. 1999; 6(4):43-9.

6. Burg KJL, Porter S, Kellam JF. Biomaterial developments for bone tissue engineering. Biomaterials. 2000; 21:2347-59.

7. Figueiredo AS. Estudo morfológico comparativo entre implantes de osso bovino desvitalizado, hidroxiapatita porosa de coral, poliuretana de mamona e enxerto ósseo autógeno, em coelhos [Tese Doutorado]. Universidade Federal de São Paulo - Escola Paulista de Medicina; 2001.

8. Silva RA. Efeito de antiinflamatórios na intregração de enxerto ósseo autógeno e de matriz óssea bovina desvitalizada, em ratos [Tese Doutorado]. Universidade Federal de São Paulo - Escola Paulista de Medicina; 2003.

9. Silva FA, Silva ES, Apolinario JCG, Baisch ALM, Alam MF, Oliveira BT, Battastini AM, Torres F, Racoski G, Lapa AJ. Estudos farmacológicos preliminares dos extratos da Casearia sylvestris Swartz Vittalle. 1986; 2:57-66.

10. Ruppelt BM. Pereira EFR, Gonçalves LC, Pereira NA. Pharmacological screening of plants recommended by folk medicine as antisnake venom: I - Analgesic and anti-inflammatory activities. Mem Inst Oswaldo Cruz. 1991; 86(suppl. 2:203-5.

11. Sato MEO. Estudo da estabilidade de uma formulaçäo na forma gel, veiculando o extrato fluido de Casearia sylvestris Sw., Flacourtiaceae ("guaçatonga") [Tese - Doutorado]. Universidade de São Paulo; 1998.

12. Sertie JA. Antiulcer activity of the crude extract from the leaves of Casearia slyvestris. Pharmaceutical Biol.. 2000; 38(2):112-9.

13. Barbosa AD, Ferreira RCV, Valente PHM. Atividade antimicrobiana de extratos fluidos de plantas medicinais brasileiras. Lecta-USF. 1994; 12(2):153-63.

14. Almeida, A. Antitumor and anti-inflammatory effects of extract from Casearia sylvestris: comparative study with Piroxicam and Meloxicam [Dissertação - Mestrado]. Universidade de São Paulo; 1999.

15. Oberlies NH, Burgess JP, Navarro HA, Pinos RE, Fairchild CR, Peterson RW, Soejarto DD, Farnsworth NR, Kinghorn AD, Wani MC, Wall ME. Novel bioactive clerodane diterpenoids from the leaves and twigs of Casearia sylvestris. J Nat Prod. 2002; 65(2):959.

16. Bostrom MPG, Yang X, Koutras IK. Biologics in bone healing. Curr Opin Orthop. 2000; 11:403-12.

\section{Agradecimentos}

Os autores agradecem à Profa. Dra. Elenir Rose Jardim Cury Pontes pela análise estatística; à Profa. Dra. Soraya Sólon pela análise cromatográfica do decocto e à Técnica de Laboratório Rosana Oliveira de Souza Pereira pelo zelo com os animais.

Correspondência:

Conflito de interesse: nenhum

Fonte de financiamento: Fundação Manoel de Barros

Maria Cristina Pita Sassioto

Avenida Joana D’Arc, 954/203 Bl 34

Tel: (67)387-7513

79070-170 Campo Grande - MS

xxaxxi@brturbo.com

Recebimento: 12/08/2004

Revisão: 21/09/2004

Aprovação: 15/10/2004

\section{Como citar este artigo:}

Sassioto MCP, Cardoso Filho N, Facco GG, Sodré ST, Neves N, Purisco SU, Farias AG. Efeito da Casearia sylvestris no reparo ósseo com matriz óssea bovina desvitalizada em ratos. Acta Cir Bras [serial online] 2004 Nov-Dez;19(6). Disponível em URL: http://www.scielo.br/acb [também em CD-ROM].

*Figura colorida disponível em URL:http://www.scielo.br/acb 